\title{
ENDOSCOPIC DACRYOCYSTORHINOSTOMY WITH OR WITHOUT INTRAOPERATIVE APPLICATION OF MITOMYCIN C- A COMPARATIVE STUDY
}

\author{
Anupama Anisseril1, Deepa Reghunathan ${ }^{2}$, Balakrishnan Edacheriyan ${ }^{3}$, Aswin Mukundan 4 , Rajesh K. P5, Shaharbana $B^{6}$ \\ 1 1Junior Resident, Department of Otorhinolaryngology (ENT), Academy of Medical Sciences, Pariyaram, Kannur, Kerala. \\ ${ }^{2}$ Associate Professor, Department of Otorhinolaryngology (ENT), Academy of Medical Sciences, Pariyaram, Kannur, Kerala. \\ ${ }^{3}$ Professor, Department of Otorhinolaryngology (ENT), Academy of Medical Sciences, Pariyaram, Kannur, Kerala. \\ ${ }^{4}$ Assistant Professor, Department of Otorhinolaryngology (ENT), Academy of Medical Sciences, Pariyaram, Kannur, Kerala. \\ ${ }^{5}$ Senior Resident, Department of Otorhinolaryngology (ENT), Academy of Medical Sciences, Pariyaram, Kannur, Kerala. \\ 6Junior Resident, Department of Otorhinolaryngology (ENT), Academy of Medical Sciences, Pariyaram, Kannur, Kerala.
}

\begin{abstract}
BACKGROUND

Endoscopic Dacryocystorhinostomy (DCR) is one of the increasingly recognised surgeries performed by an Otorhinolaryngologist in the recent years. It is the surgery of choice for post saccular lacrimal obstruction. The most common cause of failure of dacryocystorhinostomy is secondary to reclosure of stoma due to scarring, adhesion and granulation tissue formation. Several modifications have been put forward by various authors in order to shorten operative time, reduce complications and to improve overall success rate of this surgery.

The aim of this study is to study the efficacy and safety of intraoperative use of Mitomycin C in endoscopic dacryocystorhinostomy.
\end{abstract}

\section{MATERIALS AND METHODS}

Study Design- Randomised controlled trial.

This study was conducted in Department of Otolaryngology and Head and Neck Surgery, Academy of Medical Sciences, Pariyaram, Kerala, India. A total of 30 patients who underwent Endoscopic Dacryocystorhinostomy for post saccular lacrimal obstruction during the period of 15 months from June 2014 to August 2015 were included in the study. On the basis of randomisation technique by using lottery method, patients were assigned to two groups of 15 each; the Mitomycin C (MMC) group in which we used topical Mitomycin C $(0.5 \mathrm{mg} / \mathrm{mL})$ and the Control group without using Mitomycin C. Each patient was followed up with lacrimal syringing, tear meniscus height (TMH) assessment and endoscopic inspection of DCR stoma. The complications and the surgical outcomes were compared between the two groups.

\section{RESULTS}

A total of 30 Endoscopic Dacryocystorhinostomy was performed. At the end of 6 months followup period, 100\% of patients in MMC group were asymptomatic when compared to $86.67 \%$ patients in the control group. The complications observed in the control group were granulation at the stomal site and synechiae formation.

\section{CONCLUSION}

From the present study, we conclude that use of intraoperative Mitomycin C application over the DCR stomal edges can be recommended as a safe and effective method of prevention of postoperative stomal stenosis.

\section{KEYWORDS}

Mitomycin C, Endoscopic Dacryocystorhinostomy, Post-operative Stomal Stenosis.

HOW TO CITE THIS ARTICLE: Anisseril A, Reghunathan D, Edacheriyan B, et al. Endoscopic dacryocystorhinostomy with or without intraoperative application of mitomycin c- a comparative study. J. Evolution Med. Dent. Sci. 2017;6(66):4773-4778, DOI: 10.14260/Jemds/2017/1034

\section{BACKGROUND}

Epiphora or excessive lacrimation is a common annoying ophthalmic symptom altering the refraction leading to social and functional embarrassment to the patient. It may be secondary to excessive production of tears due to chronic

Financial or Other, Competing Interest: None.

Submission 10-07-2017, Peer Review 04-08-2017,

Acceptance 10-08-2017, Published 17-08-2017.

Corresponding Author:

Dr. Deepa Reghunathan,

Associate Professor,

Department of Otolaryngology,

Head and Neck Surgery,

Academy of Medical Sciences,

Pariyaram, Kannur, Kerala, India.

E-mail: drdeepaent@gmail.com

DOI: $10.14260 /$ jemds $/ 2017 / 1034$

\section{(c) (i) $(5)$}

inflammatory conditions like entropion, ectropion and trichiasis or proximal obstruction of drainage system at the level of punctum or common canaliculus. ${ }^{1}$ Causes of epiphora are varied, but most common and often under-recognised cause is the upper lacrimal system obstruction. About $87 \%$ of epiphora is due to chronic dacryocystitis, ${ }^{2}$ preferentially more common in adults over middle life from $5^{\text {th }}$ to $7^{\text {th }}$ decade. ${ }^{3-6}$ The advent of dacryocystorhinostomy (DCR), a surgical procedure done to drain lacrimal sac in intra-saccular and post-saccular obstruction proved to be a revolution in treatment of epiphora. Caldwell first described endonasal approach in $1893^{7}$ and was modernised by the endonasal endoscopic technique in 1989 by McDonough and Meiring. ${ }^{8}$ DCR surgically bypasses the distal portion of the lacrimal apparatus and creates a new outflow tract in the lateral wall of nasal cavity instead of the normal opening below inferior turbinate. The procedure is specifically designed to manage obstructions of lacrimal sac 
and duct. The advantage of endoscopic over external DCR include absence of external scar, maintenance of lacrimal pumping mechanism, shorter recovery time and lower overall postoperative morbidity. ${ }^{4}$ The success rate of DCR was found to be ranging from $84 \%$ to $94 \%,{ }^{9}$ whereas studies have also shown a failure rate of $11 \%-28 \%$ with an average of $9.4 \%$ necessitating improvement of the technique.10 The two main causes of DCR failure are obstruction of common canaliculus and closure of osteotomy site by fibrosis and scar formation. So by inhibiting fibrous growth and subsequent scarring of the osteotomy site by using anti-proliferative agents like Mitomycin C over the anastomosed flaps and osteotomy site, the failure rate may be decreased.10

\section{MATERIALS AND METHODS}

This study was conducted in the Department of Otolaryngology and Head and Neck Surgery, Academy of Medical Sciences, Pariyaram, Kerala, India on 30 patients with acquired nasolacrimal duct obstruction during the period from June 2014 to August 2015.

Patients who attended ENT OPD with acquired nasolacrimal duct obstruction and who gave consent to enrol in the study was included in the study.

\section{Inclusion Criteria}

The inclusion criteria were chronic dacryocystitis, history of recurrent epiphora for 3 months or more, not responding to medical therapy, mucocoele, acute on chronic dacryocystitis and pyocoele in patients above the age of 12 years.

\section{Exclusion Criteria}

Patients with acute dacryocystitis and tumours of lacrimal apparatus, pre-saccal obstruction, patients with atrophic rhinitis, nasal polyposis and chronic granulomatous conditions and other local inflammatory and neoplastic conditions were excluded from the study.

\section{Randomisation Technique}

Patients were assigned to the two groups, i.e. experimental and control using lottery method. Thirty identical chits were prepared and numbered serially from 1 to 30 . After folding, these chits were put in a box and shuffled. When the patient came, we blindfoldedly picked a chit for the particular patient. If the chit contained an even number, the patient was assigned to the experimental group and if it was an odd number the patient was allocated to the control group.

The study was approved by Ethics Committee of Academy of Medical Sciences, Pariyaram, India and informed consent was obtained from each patient prior to surgery.

In all patients presenting with epiphora, we confirmed nasolacrimal duct obstruction by syringing of lacrimal punctum and observing for regurgitation. A detailed history was taken followed by a preliminary diagnostic nasal endoscopy to rule out associated nasal conditions like atrophic rhinitis, nasal polyposis and chronic granulomatous conditions, deviated nasal septum and Middle Turbinate Hypertrophy (MTH). We did a Tear Meniscus Height (TMH) assessment using a slit-lamp with the help of Ophthalmology Department for each patient and findings were recorded. It was assessed using a slit beam height of slit lamp. Fluorescein dye was used to confirm the TMH if required. TMH proved an economical and non-invasive tool to assess nasolacrimal duct obstruction. The limitation of this variable was the difficulty to interpret when patient had a co-existent dry eye, especially in elderly patients.

Most of the cases underwent surgery under general anaesthesia (GA) and same surgical technique was adopted in both groups. Nasal preparation was done by applying packs soaked in 4\% xylocaine with 1 in 2,00,000 adrenaline, which was kept in the three endoscopic passes. After preliminary nasal endoscopy, septoplasty was done if there was difficulty to access the DCR site. Infiltration was done with $2 \%$ xylocaine and 1 in 1,00,000 adrenaline at the lateral wall of nose above and anterior to middle turbinate (Axilla of middle turbinate) and middle meatus with 23 -guage $1^{1 / 2}$ inch needle. Then frontal process of maxilla was identified as a ridge in front of middle turbinate. The anterior border of uncinate process was identified posterior to it with a probe. Lacrimal bone lies between these two landmarks. Two incisions are made on the lateral wall of nose with a sickle knife; superior one starting just anterior to the upper attachment of middle turbinate extending about 0.5 to $0.7 \mathrm{~cm}$ anteriorly and lower incision just at upper border of inferior turbinate and parallel to it. Then both incisions are joined anteriorly creating a posteriorly based mucoperiosteal flap. The flap was elevated using a Freer's elevator and thus base of lacrimal fossa was exposed. Using a 2 mm Kerrison's bone punch, bone of lacrimal fossa is removed till the sac is adequately exposed. Bowman's lacrimal probe was used to tent the medial wall of the sac and an incision was made in the postero-inferior aspect of medial wall of the sac with a sickle knife. Medial wall of sac was removed with Blakesley forceps. Posteriorly based mucosal flap was excised at the level of the maxillary line. Lacrimal syringing and probing was done intraoperatively to confirm patency. Intraoperatively, topical Mitomycin C $(0.5 \mathrm{mg} / \mathrm{mL}$ for 2.5 minutes) was applied to the mucosal border of DCR osteotomy site under endoscopic visualisation with maximum care taken to ensure circumferential contact with the sponge in all subjects in the MMC group. A change in the colour of the mucosa (blanching) was noticed immediately after successful application. Similarly, in the control group, normal saline was applied at the stomal site intraoperatively. Light nasal packing was done with medicated roller gauze, which was removed on the first post-operative day. All surgeries were performed by a single surgeon using the above technique.

In all patients, syringing was done to confirm patency of stoma on $1^{\text {st }}$ postop day. Patient was discharged on $3^{\text {rd }}$ postop day and was asked to come for followup on the specified dates. Post-operatively, patients were given oral antibiotics, antiinflammatory agents, nasal decongestants and antibiotics with steroid eye drops. Results were assessed on the basis of subjective improvement of epiphora, endoscopic visualisation of patent stoma, tear meniscus height assessment and periodic syringing. TMH and visualisation of stoma by nasal endoscopy was done on first and $7^{\text {th }}$ post-op days, $3^{\text {rd }}$ week, $6^{\text {th }}$ week, $3^{\text {rd }}$ month, $6^{\text {th }}$ month and $9^{\text {th }}$ months. Details of all postoperative follow-ups were carefully recorded in proforma. Results were analysed with the help of appropriate statistical tests (Chisquare test and Fisher's exact test) using SSPS version 13. 


\section{RESULTS}

1) Demographic Profile

Youngest of our patients was 15 years of age and eldest 83 years with mean age being 53.5 years. Maximum number of patients was in the age group $61-70$ years. There was no significant difference in age between the two groups (Figure 1). Among the 30 patients, 22 were females $(73.3 \%)$ and 8 were males $(26.7 \%)$.

In study group (MMC group), out of the 15 patients 12 were females (80\%) and in the control group 10 (66.6\%) were females showing female predilection (Table 1).

\section{2) Distribution of Laterality of Cases}

Out of the 30 patients, 18 patient's (60\%) surgery was done on left side, 11 cases (36.7\%) on right side and in 1 case $(3.3 \%)$ bilateral surgery was done (Figure 2).

\section{3) Distribution of Case Type}

Out of 30 cases $24(80 \%)$ were primary cases, whereas 6 (20\%) were revision cases. One of the revision cases had a history of stent insertion, which was buried in granulation tissue and stoma was blocked. The granulation tissue and the stent was removed, the stoma widened and intraoperative MMC was applied. We did not use stents in any of our cases to avoid confounding errors.

\section{4) Clinical Presentation}

Out of 15 cases in MMC group, 13 presented with watering of eye, 2 with mucopurulent discharge and 6 had deviated nasal septum (DNS) (Table 2). In control group 12 presented with watering of eye, 3 with mucopurulent discharge and 8 with DNS. We also did a pre-op diagnostic nasal endoscopy to assess co-existent nasal pathologies. Out of the 30 cases, 12 (40\%) underwent an endoscopic septal correction to make working space for the procedure. One patient had co-existent sinusitis, in which we did a middle meatal antrostomy in the same sitting on the opposite side of DCR.

\section{5) Tear Meniscus Height Assessment}

In normal eyes the TMH was found around $0.2-0.3 \mathrm{~mm}$ and eyes which had nasolacrimal duct obstruction a higher value was obtained. We found moderate tear meniscal height pre-operatively in 4 cases and high in 11 cases of MMC group. In the control group, we found 6 patients had moderate and 9 patients had high TMH. During post-operative assessment at 3 months all patients in MMC group had normal TMH, whereas in the control group 2 patients who developed epiphora had high TMH. Tear meniscus height 3 months postoperatively in both the groups are shown in Table 4. From this it is evident that all the patients in the MMC group postoperatively had normal TMH (100\%), whereas $13.33 \%$ in the control method group had high TMH, even though the difference was not statistically significant $(\mathrm{P} \geq$ 0.05).

\section{6) Lacrimal Sac Syringing During Followup}

In all the patients, we did a syringing to confirm stoma patency on the $1^{\text {st }}$ post-op day. In the subsequent followups at $1^{\text {st }}$ week, $3^{\text {rd }}$ week, $3^{\text {rd }}$ month and $6^{\text {th }}$ month, we did visual assessment of the surgical stoma through nasal endoscopic examination along with assessment of symptom relief as reported by the patient. During the followup, a patient in the control group presented with epiphora due to formation of synechiae at 6 weeks. At 3 months, another patient in the control group had epiphora due to blockage of the stoma by granulation tissue (Figures 5 and 6). Thus, out of the 15 patients, 2 patients had recurrent epiphora at the end of 3 months in the control group.

At the end of 6 months followup, all patients in the Mitomycin C group showed free flow on syringing and did not report any symptoms. Patients in both the groups were further followed up and there were no failures during the specified time (Figure 7).

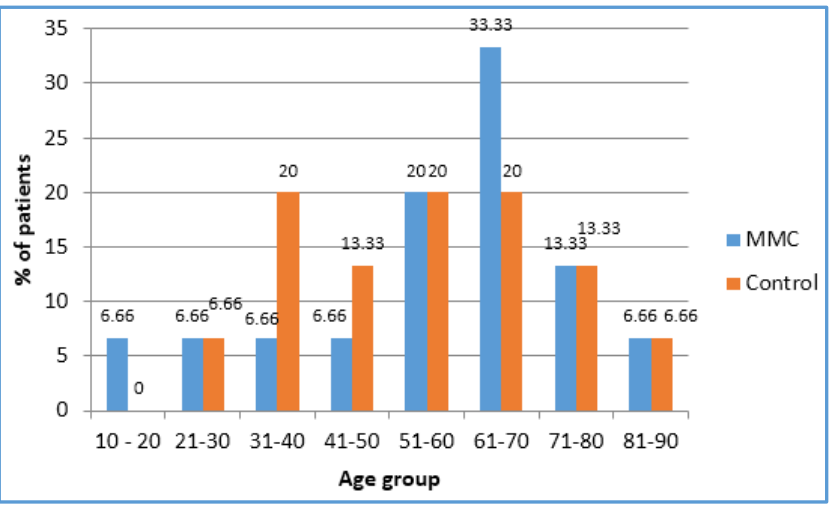

Figure 1. Percentage distribution of Age in MMC and Control Group

\begin{tabular}{|c|c|c|}
\hline Gender Distribution & MMC Group & Control Group \\
\hline Females & $12(80 \%)$ & $10(66.6 \%)$ \\
\hline Males & $3(20 \%)$ & $5(33.4 \%)$ \\
\hline
\end{tabular}

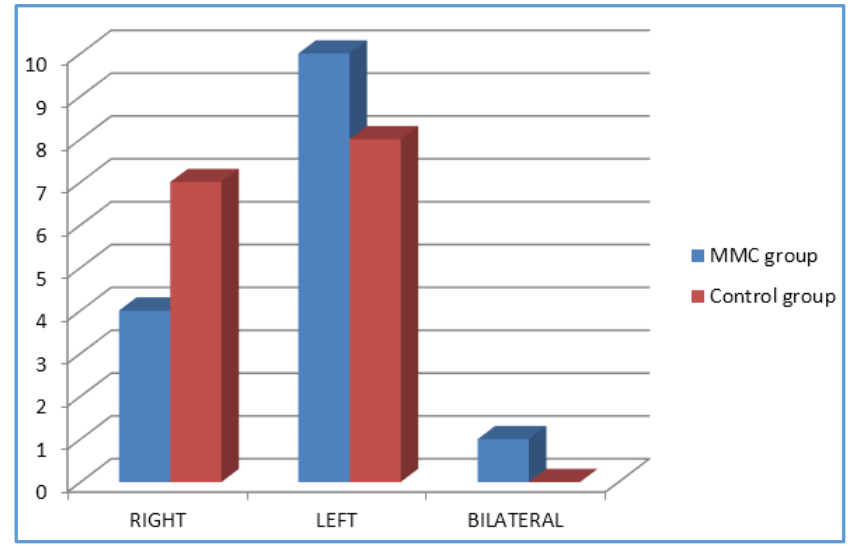

Figure 2. Distribution of Laterality of Cases

\begin{tabular}{|c|c|c|}
\hline Clinical Presentation & MMC Group & Control Group \\
\hline Watering & 13 & 12 \\
\hline Discharge & 2 & 3 \\
\hline Deviated Nasal Septum & 6 & 8 \\
\hline
\end{tabular}




\begin{tabular}{|c|c|c|c|}
\hline Tear Meniscus Height & $\begin{array}{c}\text { MMC } \\
\text { Group }\end{array}$ & $\begin{array}{c}\text { Control } \\
\text { Group }\end{array}$ & \multirow{2}{*}{ P value* } \\
\cline { 1 - 3 } Normal $(0.2-0.3)$ & 0 & 0 & \multirow{2}{*}{0.464} \\
\cline { 1 - 3 } Moderate $(0.4-0.5)$ & 4 & 6 & \\
\cline { 1 - 3 } High (> 0.5) & 11 & 9 & \\
\cline { 1 - 1 } \multicolumn{2}{|c|}{ Table 3. Tear Meniscus Height before Surgery } \\
\hline
\end{tabular}

*Using Chi-test Square test.

\begin{tabular}{|c|c|c|c|}
\hline $\begin{array}{c}\text { Tear Meniscus } \\
\text { Height }\end{array}$ & MMC Group & $\begin{array}{c}\text { Control } \\
\text { Group }\end{array}$ & P value* \\
\hline Normal & 15 & 13 & \multirow{2}{*}{0.483} \\
\cline { 1 - 3 } Moderate & 0 & 0 & \\
\cline { 1 - 3 } High & 0 & 2 & \\
\cline { 1 - 3 } Table 4. Tear Meniscus Height 3 Months after Surgery \\
\hline
\end{tabular}

*Using Fisher's exact test

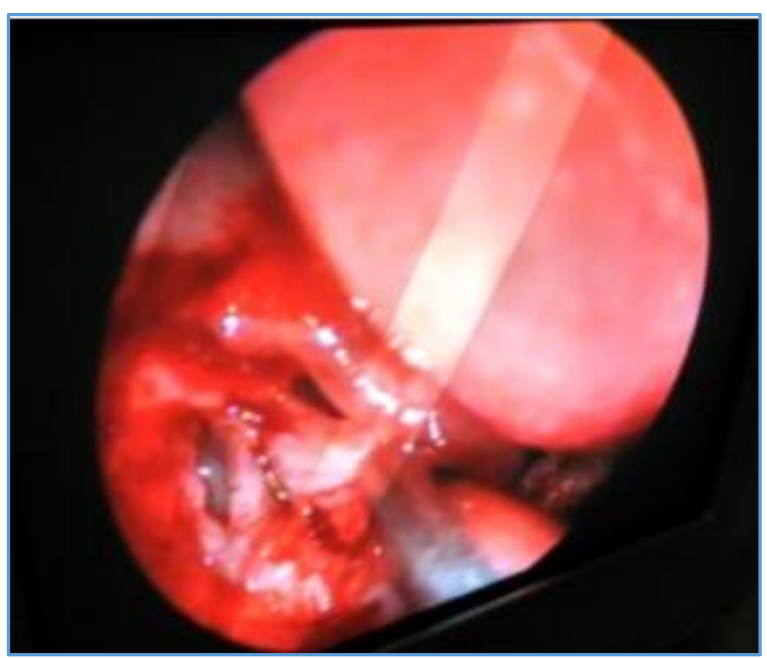

Figure 3. Photograph showing DCR Opening immediately after Mitomycin C Application

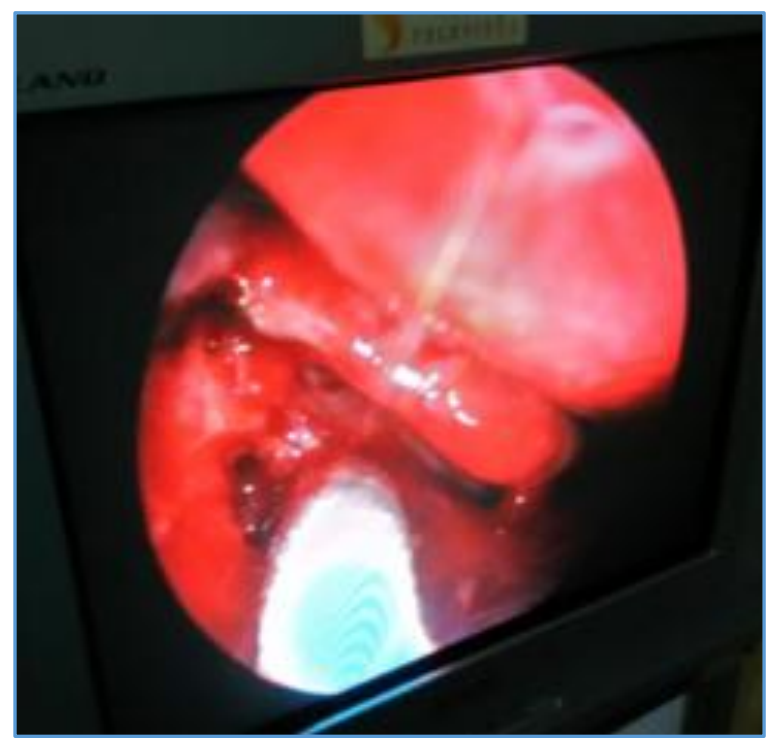

Figure 4. Photograph showing Patent DCR Opening 3 Months after Surgery in a Patient in the MMC Group

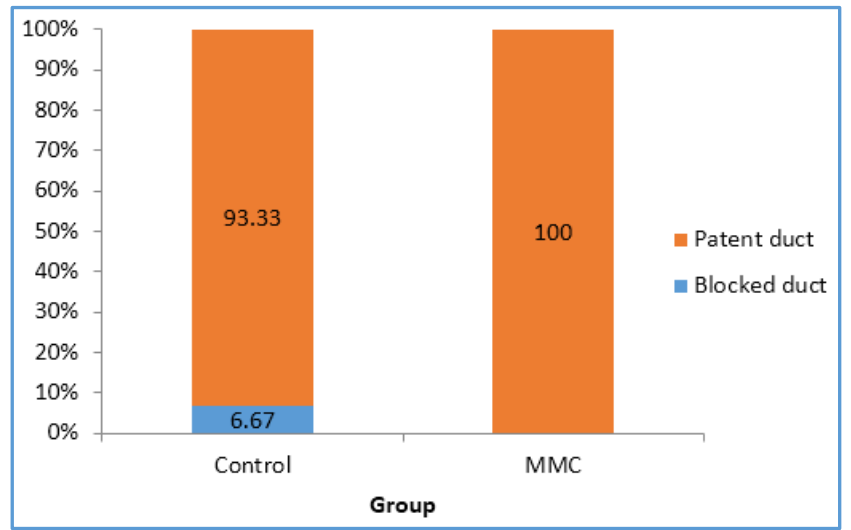

Figure 5. Duct Patency at 6 Weeks Post-Op

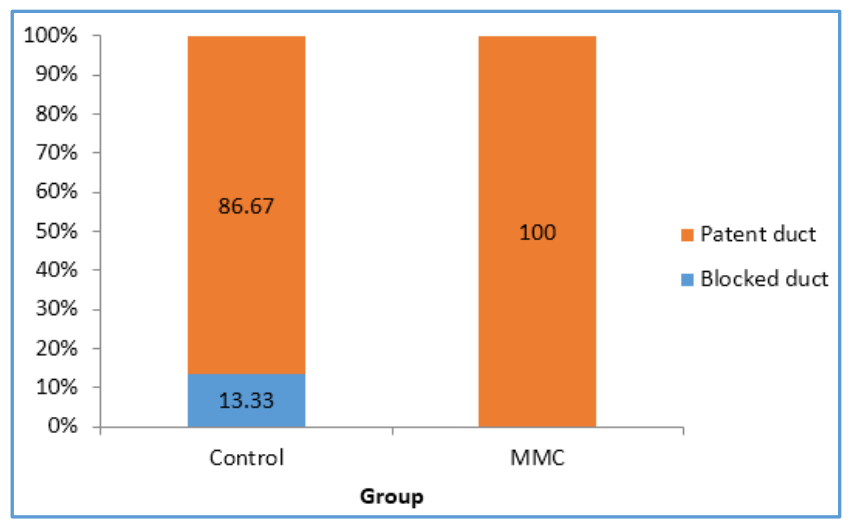

Figure 6. Duct Patency at 3 Months Post-Op

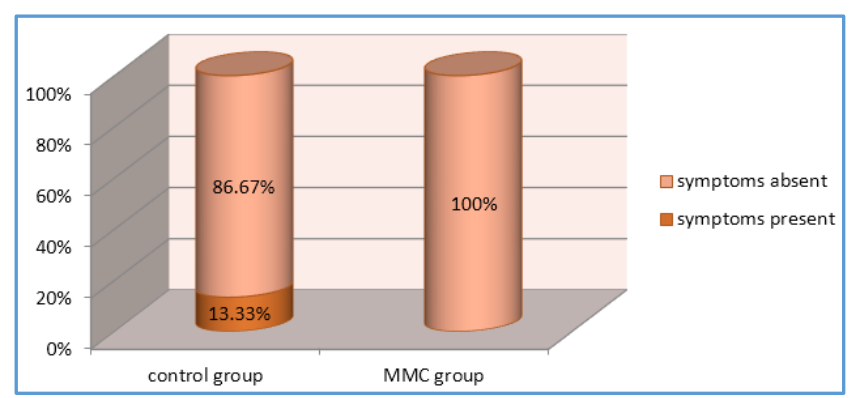

Figure 7. Symptomatic Improvement at 6 Months Post-Op

\section{DISCUSSION}

Chronic dacryocystitis is the inflammation of the lacrimal sac. It is usually caused by bacteria converting the sac into a reservoir of infection leading to potential damage to cornea and soft-tissues of orbit. It is one of the common cause of epiphora and is more common in middle aged. Peak age of incidence is $5^{\text {th }}$ to $7^{\text {th }}$ decade. ${ }^{10}$ The obstruction to the lacrimal drainage system can be relieved by a Dacryocystorhinostomyexternal or internal. In experienced hands, endoscopic DCR is a very successful surgical procedure. Both external and internal routes have a failure rate ranging from 0 to $18 \%$ and the main cause of failure is blockage of osteotomy site due to granulation tissue, scarring and formation of adhesions and synechiae in the nasal cavity.7,11,12 So antimetabolites like Mitomycin $\mathrm{C}$ and 5-fluorouracil can be used to reduce the fibrous tissue growth around the stoma keeping the stoma patent for a longer time, thus increasing the longevity of the success of DCR. ${ }^{1}$ 
In the present study, in MMC group we used intraoperative topical Mitomycin C $0.5 \mathrm{mg} / \mathrm{mL}$ for 2.5 minutes in the surgical stoma of Endoscopic DCR and followed up the patient for a period of 6 months. The mean age of the sample group was around 53.5 years with female predominance. We observed that $100 \%$ of the patients in MMC group had a patent stoma at the end of 6 months when compared to $86.67 \%$ of stomal patency in the control group. But the difference was not statistically significant.

Shu Liao et $\mathrm{al}^{11}$ had reported 32 (72.7\%) eyes having normal tear meniscus height and $5(11.3 \%)$ eyes with high tear meniscus height in their control group. This was similar to our findings. Out of the 44 eyes in their MMC group, 41 (93.1\%) had normal tear meniscus height and 2 eyes (4.6\%) had high tear meniscus height. Our study showed the normal tear meniscus height in all cases in the MMC group. Thus, this finding is an indicator of efficacy of Mitomycin $\mathrm{C}$ in preventing DCR stoma stenosis, even though our sample size was smaller. A similar comparative study of DCR with and without application of Mitomycin C was conducted by Maniah Quadir et $\mathrm{al}^{13}$ in 50 patients of primary nasolacrimal duct obstruction, ${ }^{51}$ in which $0.2 \mathrm{mg} / \mathrm{mL}$ of MMC was applied over the stoma for 5 minutes. They followed up the patients on 1st day, $1^{\text {st }}, 3^{\text {rd }} 6^{\text {th }}$ weeks, $3^{\text {rd }}$ and $6^{\text {th }}$ months. They had a female preponderance in their study group (72\%) similar to our study (73.3\%). In their study at the end of 6 months, $96 \%$ of the MMC group were symptom free. Our study did not show any recurrence of symptoms in MMC group. The control group in their study were symptom free in $80 \%$ compared to $86.7 \%$ of symptom free patients in our control group.

In the study conducted by Maniah Quadir, Andleeb Ahangar and colleagues, ${ }^{13} 4$ cases (16\%) had high tear meniscus height at the end of 6 months compared to 2 cases $(13.3 \%)$ of our control group. In the MMC group they found 1 eye (4\%) with high tear meniscus height, whereas none of our patients in MMC group had a high tear meniscus height postoperatively.

Effect of Mitomycin C on revision Endoscopic DCR was studied by Ozkiris $\mathrm{M}$ et al in 54 patients. ${ }^{14}$ Their study group consisted of 28 patients with almost equal number of patients in control group. Here $0.5 \mathrm{mg} / \mathrm{mL}$ of MMC was placed at the osteotomy site for 5 minutes similar to our study. Mean followup period was 12.7 months. The procedure with adjunctive MMC was found to be successful in $85.71 \%$ of cases, whereas we found no recurrence in any of our cases including the revision cases in MMC group.

In another study by Santhosh Kumar Prabhakar ${ }^{15}$ et al, the success rate was $90 \%$ with Mitomycin C as compared to $80 \%$ without mitomycin $\mathrm{C}$, even though there was no statistical difference in the results of two groups.

However, Kulkarni GP et al ${ }^{16}$ in their comparative study in 50 patients with and without Mitomycin $\mathrm{C}$ did not find any statistically significant benefit ( $96 \%$ vs $92 \%$ ) for the adjunct use of Mitomycin C.

The 2 failed cases in the control group were subjected to further ENT evaluation. One of the case had synechiae blocking the nasolacrimal drainage and the other had granulation tissue blocking the DCR stoma.
Despite the literatures suggesting epistaxis, delayed wound healing, mucosal necrosis and wound infection, in our study we did not encounter any significant adverse effects for MMC application at DCR site during the six months followup. The only finding we observed was a prolonged congestion of the stoma site, which might be due to prolonged healing. This finding was also in agreement with the findings of Shu Liao and colleagues. Although, we could not reach a statistically significant result $(P \geq 0.05)$ with the small sample size and relatively shorter followup period, the clinical results obtained in the study could prove that intra-operative topical application of Mitomycin C could be a safe and effective adjuvant to prevent post-operative DCR stoma stenosis in endoscopic DCR.

Limitations of the study include the small sample size and followup period.

\section{CONCLUSION}

From the present study, we conclude that use of intraoperative Mitomycin C application over the DCR stomal edges can be recommended as a safe and effective method of prevention of postoperative stomal stenosis. However, prospective studies with larger sample size with longer followup period may be advisable.

\section{REFERENCES}

[1] Fergie N, Jones NS. Dacryocystorhinostomy: ScottBrown's otolaryngology, head and neck surgery. $7^{\text {th }}$ edn. Chapter 133, CRC Press 2008:1689-98.

[2] Jacobs BH. Symptomatic epiphora. Br J of Oph 1959;43(7):415-34.

[3] Nerad JA. Lacrimal surgery, section VI. In: Bosniak Stephen (edr). Principles \& practice of ophthalmic plastic and reconstructive surgery. $1^{\text {st }}$ edn. Philadelphia: WB Saunders Company 1996:729-834.

[4] Gurler B, San I. Long-term follow-up outcomes of nonlaser intranasal endoscopic dacryocystorhinostomy: how suitable and useful are conventional surgical instruments? Eur J Ophthalmol 2004;14(6):453-60.

[5] Elder DS, Faul MPA. Diseases of lacrimal passages. In: Elder D (edr). The ocular adnexa in system of ophthalmology. St Louis Mosby Company 1974:675773.

[6] Iliff CE. A simplified dacryocystorhinostomy.19541970. Arch Ophthal 1971;85(5):586-91.

[7] Pico G. A modified technique of external dacryocystorhinostomy. Am J of Oph 1971;72(4):67990.

[8] Caldwell GW. Two new operations for obstruction of the nasal duct, with preservation of the canaliculi. Am J Ophthalmol 1893;10:189-91.

[9] McDonogh M, Meiring JH. Endoscopic transnasal dacryocystorhinostomy. J Laryngol Otol 1989;103(6):585-7.

[10] Leong SC, Macewen CJ, White PS. A systematic review of outcomes after dacryocystorhinostomy in adults. Am J Rhinol Allergy 2010;24(1):81-90. 
[11] Liao S, Kao S, Tseng J, et al. Results of intraoperative mitomycin $\mathrm{C}$ application in dacryocystorhinostomy. $\mathrm{Br}$ J Ophthalmol 2000;84(8):903-6.

[12] Herzallah I, Alzuraiqi B, Bawazeer N, et al. Endoscopic dacryocystorhinostomy (DCR): a comparative study between powered and non-powered technique. J Otolaryngol Head Neck Surg 2015;44:56.

[13] Qadir M, Ahangar A, Dar MA, et al. Comparative study of dacryocystorhinostomy with and without intraoperative application of mitomycin C. Saudi J Ophthalmol 2014;28(1):44-8.

[14] Ozkiris M, Ozkiris A. Endoscopic dacryocystorhinostomy not using canalicular silicone intubation tube with and without mitomycin C: a comparative study. Eur J Ophthalmol 2012;22(3): 320-5.
[15] Prabhakar SK, Ravishankar C, Satish HS, et al. A prospective comparative study of outcomes of primary endoscopic dacryocystorhinostomy with and without mitomycin-C. IOSR Journalof Dental and Medical Sciences 2015;14(1):29-33.

[16] Kulkarni GP, Handal AS. Comparative study of endonasal dacryocystorhinostomy with and without adjunctive topical use of mitomicin C. Int J Res Med Sci 2017;5(7):3208-13. 